Jurnal REKSA: Rekayasa Keuangan, Syariah, dan Audit

p-ISSN: 2089-6581 | e-ISSN: 2614-3720

JURNAL REKSA

Rekayasa kouangan, Syariah, dan Audi

Vol. 07 , No. 01,2020 , pp. 55-72

\title{
STUDI FAKTOR PENENTU KINERJA KARYAWAN PT. HASJRAT ABADI PALU
}

\section{Syamsul}

Sekolah Tinggi Ilmu Ekonomi Panca Bhakti Palu

Email: syamsulsyahrir@gmail.com

Fadel Muhammad

Sekolah Tinggi Ilmu Ekonomi Panca Bhakti Palu

Email: fadellajamessang@gmail.com

\begin{abstract}
This study aims to determine the effect of work environment, work culture, work motivation, job satisfaction, work discipline, and work stress on employee performance. This type of research is quantitative research. The research sample was 63 employees of PT. Hasjrat Abadi Palu. The results of regression analysis show that the work environment, work culture, job satisfaction, and job stress partially have a positive and significant effect on employee performance. Meanwhile, work motivation and work discipline do not have a significant effect on employee performance. The results can be used as a source of information in determining company policies to improve employee performance. In addition, these findings can be used as a reference for further research interested in discussing employee performance.
\end{abstract}

Keywords: Employee Performance, Determinants.

\section{PENDAHULUAN}

Di era digital saat ini, perkembangan dunia bisnis ditandai oleh ketatnya persaingan dan cepatnya perubahan lingkungan, sehingga menjadi semakin sulit diprediksi. Kondisi inilah yang mengakibatkan, setiap entitas (publik dan bisnis) dituntut untuk terus berubah dan berbenah, agar dapat memenangkan persaingan tersebut. Oleh karena itu, dibutuhkan sumber daya manusia yang mampu berinovasi, dapat bekerja lebih baik, dan lebih cepat. Sebab, secanggih apapun sumber daya yang dimiliki oleh entitas, baik itu berupa modal, metode, dan mesin tidak berarti apa-apa atau tidak dapat memberikan hasil yang optimal. Apabila tidak ditopang oleh sumber daya manusia yang memiliki kinerja optimal (Adha, Qomariah and Hafidzi, 2019). Dengan demikian, sumber daya manusia merupakan aset yang paling berharga untuk mencapai tujuan. Artinya, suatu entitas dituntut mampu menciptakan situasi dan kondisi yang dapat mendorong dan memungkinkan mereka untuk terus berkembang, baik dari sisi kemampuan maupun keterampilannya supaya dapat berkinerja dengan baik. Dalam konteks penelitian ini, sumber daya manusia adalah orang yang bekerja di dalam sebuah perusahaan, dengan kata lain karyawan suatu perusahaan.

Mengingat, kinerja karyawan sejalan dengan peningkatan kinerja perusahaan. Lebih dari itu, kinerja karyawan juga selalu disandingkan dengan kemampuan perusahaan 
untuk beradaftasi ditengah ketatnya persaingan dan keluar sebagai pemenang. Oleh karena itu, penting untuk diketahui faktor apa saja yang menjadi faktor penentu kinerja karyawan. Mangkunegara (2005) yang diikuti oleh Primandaru, Tobing and Prihatini (2018) menyatakan bahwa kinerja karyawan dapat dibentuk dengan berbagai faktor, seperti motivasi kerja, kepuasan kerja, lingkungan kerja, dan disiplin kerja. Selanjutnya, hasil penelitian Adha, Qomariah and Hafidzi (2019) yang menguji pengaruh motivasi kerja, lingkungan kerja, dan budaya kerja terhadap kinerja karyawan. Populasi penelitian mereka adalah karyawan Dinas Sosial Kabupaten Jember. Hasil pengujian hipotesis, terbukti motivasi kerja tidak berpengaruh terhadap kinerja karyawan. Sementara itu, lingkungan kerja dan budaya kerja ditemukan memiliki pengaruh positif dan signifikan terhadap kinerja karyawan. Setyawati, Aryani and Ningrum (2018) melakukan penelitian yang bertujuan untuk menguji pengaruh stres kerja dan disiplin kerja terhadap kinerja karyawan di Stasiun Manggarai, Jakarta Selatan. Data yang diolah adalah data primer yang bersumber dari jawaban responden atas kuisioner yang disebarkan kepada 115 karyawan. Hasil penelitian menunjukkan stres kerja berpengaruh negatif terhadap kinerja karyawan, begitupula disiplin kerja berpengaruh positif terhadap kinerja karyawan. Selain itu, Primandaru, Tobing and Prihatini (2018) yang membuktikan bahwa motivasi kerja, lingkungan kerja, disiplin kerja secara parsial berpengaruh terhadap kinerja karyawan PT. Kereta API Indonesia (Persero) DAOP IX Jember.

Berdasarkan agumentasi dan temuan penelitian sebelumnya, penelitian ini mencoba membahas enam faktor penentu kinerja karyawan yang diidentifikasi. Enam faktor tersebut, yaitu lingkungan kerja, budaya kerja, motivasi kerja, kepuasan kerja, disiplin kerja, dan stres kerja. Dengan demikian, penelitian ini mencoba membuktikan (menguji) kembali apakah hasil yang sama yang ditemukan pada penelitian sebelumnya, juga ditemukan apabila dilakukan pada karyawan PT. Hasjrat Abadi Palu.

\section{TINJAUAN PUSTAKA}

\section{Kinerja Karyawan}

Menurut Adha, Qomariah and Hafidzi (2019) kinerja karyawan adalah suatu hasil yang dicapai oleh karyawan, dimana hasil kerja tersebut dapat diperlihatkan buktinya secara konkrit serta terukur. Setyawati, Aryani and Ningrum (2018) berpendapat bahwa kinerja karyawan adalah hasil yang dicapai oleh seseorang karyawan dalam melaksanakan tugasnya sesuai dengan tanggungjawab yang diberikan kepadanya. Menurut Riyadi, (2011) penentu kinerja karyawan dapat dibagi kedalam dua faktor utama, yaitu faktor internal dan faktor eksternal. Faktor internal merupakan faktor yang berkaitan dengan perilaku (sifat-sifat) seseorang, meliputi sikap, sifat-sifat kepribadian, sifat fisik, keinginan atau motivasi, latar belakang budaya, dan variabel personal lainnya. Sementara itu, faktor eksternal merupakan faktor yang berasal dari lingkungan, kepemimpinan, tindakantindakan rekan kerja, jenis latihan dan pengawasan, sistem upah, dan lingkungan sosial. Kemudian, Setyawan (2018) dalam penelitiannya mencatat tujuh faktor yang mempengaruhi kinerja karyawan yaitu motivasi karyawan, pengembangan karyawan, lingkungan kerja, sistem penghargaan karyawan, kepuasan karyawan, perilaku karyawan, 
dan gaya kepemimpinan. Penelitian ini, berfokus menguji pengaruh lingkungan kerja, budaya kerja, motivasi, kepuasan kerja, disiplin kerja, dan stres kerja terhadap kinerja karyawan.

\section{Pengembangan Hipotesis Penelitian}

\section{Pengaruh Lingkungan Kerja Terhadap Kinerja Karyawan}

Siagian (2014:103), berpendapat bahwa manfaat lingkungan kerja yang kondusif yaitu menciptakan gairah kerja, serta berimplikasi pada produktivitas dan peningkatan prestasi kerja. Penelitian Adha, Qomariah and Hafidzi (2019) menegaskan bahwa lingkungan kerja berpengaruh terhadap kinerja karyawan. Begitu pula, hasil penelitian Effendy and Fitria (2019) pada PT Modernland Realty Tbk, Jakarta Selatan juga menjelaskan pengaruh positif lingkungan kerja terhadap kinerja karyawan. Dengan demikian, lingkungan kerja yang kondusif menciptakan rasa aman, sehingga memungkinkan karyawan untuk dapat bekerja secara optimal. Dengan kata lain, bahwa karyawan yang menyenangi lingkungan kerja tempat dia bekerja, tentunya dia akan merasa nyaman dan betah di tempat kerjanya untuk melakukan aktivitas. Sehingga, waktu kerja dapat dipergunakan secara efektif yang pada akhirnya meningkatkan kinerja karyawan. Oleh karena itu hipotesi 1 penelitian ini adalah:

\section{H1: Terdapat pengaruh positif lingkungan kerja terhadap kinerja karyawan PT. Hasjrat} Abadi Palu

\section{Pengaruh Budaya Kerja Terhadap Kinerja Karyawan}

Anggeline, Meitriana and Sujana (2019) menyatakan budaya kerja memiliki tujuan utama dalam pelaksanaan kegiatan operasional perusahaan. Yaitu, mengubah sikap dan juga perilaku SDM, sehingga pada gilirannya dapat meningkatkan kinerja. Sekaligus, sebagai upaya strategis didalam menghadapi berbagai tantangan bisnis dimasa yang akan datang. Hasil penelitian (lihat, Anggeline, Meitriana and Sujana, 2019; Panggabean, Soekapdjo and Tribudhi, 2020; Silvia, Bagia and Cipta, 2016) menemukan budaya kerja berpengaruh signifikan terhadap kinerja karyawan. Artinya, penelitian tersebut berhasil membuktikan bahwa budaya kerja dapat mendorong peningkatan kinerja karyawan. Oleh karena itu, dapat dikatakan bahwa semakin positif budaya kerja karyawan berimplikasi pada peningkatan kinerja kerjanya. Maka, hipotesis 2 diajukan:

H2: Terdapat pengaruh positif budaya kerja terhadap kinerja karyawan PT. Hasjrat Abadi Palu

\section{Pengaruh Motivasi Kerja Terhadap Kinerja Karyawan}

Menurut Adha, Qomariah and Hafidzi (2019) hubungan motivasi, gairah kerja terhadap hasil optimal memiliki pola yang linear, dengan kata lain bahwa pemberian motivasi kerja yang baik mengarah pada peningkatan gairah kerja karyawan. Peningkatan gaya kerja berdampak pula pada pencapaian hasil kerja yang lebih tinggi atau sesuai dengan sasaran yang telah ditetapkan. Riyadi (2011) menunjukkan bahwa motivasi kerja berpengaruh 
terhadap kinerja karyawan pada perusahaan manufaktur di Jawa Timur. Sejalan dengan itu, Mulyadi and Syafitri (2015) juga membuktikan motivasi kerja berpengaruh terhadap kinerja karyawan pada Bank Jabar Banten Syariah Cabang Bogor. Begitupula, penelitian Ayer, Pangemanan and Rori (2016) pada Dinas Pertanian Kabupaten Supiori; Nababan and Siagian (2020) pada Sanwa Enginerring Batam; Asmawiyah and Mukhtar (2020) pada PT. Perkebunan Nusantara XIV Makassar; Heny (2015) pada Sekretariat DPRD Kabupaten Madiun, juga menjelaskan bahwa motivasi kerja berpengaruh positif terhadap kinerja pengawai. Artinya, motivasi kerja yang tinggi berbanding lurus dengan kinerja karyawan. Atas dasar itu, hipotesis 3 disusun sebagai berikut:

\section{H3: Terdapat pengaruh positif motivasi kerja terhadap kinerja karyawan PT. Hasjrat} Abadi Palu

\section{Pengaruh Kepuasan Kerja Terhadap Kinerja Karyawan}

Panggabean, Soekapdjo and Tribudhi (2020) mengatakan bahwa kepuasan kerja adalah suatu konsep yang berdimensi jamak, yang meliputi kepuasan terhadap gaji, rekan kerja, promosi, kondisi kerja, dan prestasi kerja. Senada dengan itu, Titisari (2014:18) juga menyatakan bahwa kepuasan kerja merupakan suatu ungkapan perasaan atau sikap seseorang terhadap pekerjaannya, kesempatan promosi, rekan kerja, pengawasan dan perasaan puas atas pekerjaannya itu. Hasil penelitian dari Panggabean, Soekapdjo and Tribudhi (2020) membuktikan bahwa kepuasan kerja berpengaruh positif terhadap kinerja karyawan PT Kereta Api Indonesia (Persero) Daop IX Jember. Maknanya, kepuasan kerja yang tinggi berdampak pada peningkatan kinerja karyawan. Dengan demikian, H4 berbunyi:

\section{H4: Terdapat pengaruh positif kepuasan kerja terhadap kinerja karyawan PT. Hasjrat} Abadi Palu

\section{Pengaruh Disiplin Kerja Terhadap Kinerja Karyawan}

Musanef (1996) mengemukakan bahwa disiplin kerja setiap pegawai selalu mempengaruhi hasil prestasi kerja atau kinerja pengawai tersebut. Senada dengan itu, Primandaru, Tobing and Prihatini (2018) juga mengungkapkan bahwa manfaat yang didapatkan perusahaan ketika disiplin kerja itu dimiliki oleh setiap karyawan, dan membudaya dikalangan karyawan adalah untuk mendukung tercapainya tujuan perusahaan (organisasi). Artinya, disiplin kerja menitikberatkan kepada pengawai untuk taat dan patuh terhadap aturan atau standard kerja yang ditetapkan, untuk mencapai suatu tujuan. Hasil penelitian Ayer, Pangemanan and Rori (2016) membuktikan bahwa disiplin kerja berpengaruh positif dan signifikan terhadap kinerja pegawai Dinas Pertanian Kabupaten Supiori. Hasil itu, sesuai dengan temuan Setyawati, Aryani and Ningrum (2018) yang menunjukkan bahwa disiplin kerja memiliki pengaruh signifikan terhadap kinerja karyawan Stasiun Manggarai, Jakarta Selatan. Logikanya, melalui disiplin kerja yang tinggi produktivitas atau kinerja karyawan pada intinya dapat ditingkatkan. Oleh karena itu, hipotesis 5 terbentuk berikut ini: 
H5: Terdapat pengaruh positif disiplin kerja terhadap kinerja karyawan PT. Hasjrat Abadi Palu

\section{Pengaruh Stres Kerja Terhadap Kinerja Karyawan}

Menurut Ahmed (2013) yang diikuti Setyawati, Aryani and Ningrum (2018) stres kerja yang merupakan reaksi individu terhadap kekuatan lingkungan berpengaruh pada kinerja individu. Penelitian Prastiyo (2019) menunjukkan bahwa stres kerja berpengaruh positif terhadap kinerja karyawan JNE Cabang Madiun. Hasil yang berbeda, ditemukan oleh Leonardo Hendy Lukito and Alriani (2018), bahwa stres kerja berpengaruh negative terhadap kinerja karyawan PT. Sinarmas Distribusi Nusantara Semarang. Dengan kata lain, bahwa stres kerja memiliki pengaruh terhadap kinerja karyawan. Sehingga, hipotesis 6 penelitian ini adalah:

H6: Terdapat pengaruh positif Stres kerja terhadap kinerja karyawan PT. Hasjrat Abadi Palu

\section{METODE PENELITIAN}

\section{Populasi dan Sampel}

Populasi penelitian ini adalah karyawan PT. Hasjrat Abadi Palu. Karyawan tersebut terdapat di tiga lokasi yang berbeda, yaitu pada PT. Hasjrat Abadi Mutiara, PT. Hasjrat Abadi Ponegoro, dan PT. Hasjrat Abadi Durian. Lebih lanjut, dapat dilihat pada tabel 2 berikut:

Tabel 2. Daftar Populasi

\begin{tabular}{|c|c|c|}
\hline Lokasi Penelitian & Cabang & Populasi \\
\hline \multirow{4}{*}{ PT. Hasjrat Abadi Palu } & PT. Hasjrat Abadi Mutiara Palu & 58 \\
\hline & PT. Hasjrat Abadi Ponegoro Palu & 92 \\
\hline & PT. Hasjrat Abadi Durian Palu & 20 \\
\hline & Total & 170 \\
\hline
\end{tabular}

Sumber :HRD PT. Hasjrat Abadi Palu

Untuk menentukan jumlah sampel yang akan digunakan dalam penelitian ini digunakan dengan rumus Slovin (Umar, 2008) sebagai berikut :

$$
n=\frac{\mathrm{N}}{1+\mathrm{N} \cdot(\mathrm{e})^{2}}
$$

Dimana :

$\mathrm{n}$ = jumlah sampel

$\mathrm{N}=$ jumlah populasi

e $=$ batas toleransi kesalahan (error) 
Dalam penggunaan rumus di atas pertama-tama harus ditentukan berapa batas toleransi kesalahan yang dinyatakan dengan presentasi. Dengan batas toleransi kesalahan sebesar $10 \%(0,10)$ maka jumlah sampel yang akan digunakan dalam penelitian ini adalah :

$$
\mathrm{n}=\frac{\mathrm{N}}{1+\mathrm{N}(\mathrm{e})^{2}}=\frac{170}{1+170(0,10)^{2}}=\frac{170}{2,7}=63
$$

Sehingga jumlah sampel yang ditetapkan dalam penlitian ini adalah sebanyak 63 sampel, kemudian ditentukan masing-masing sampel berdasarkan proportione d stratified random sampling. Menurut (Sugiyono, 2014). Proportioned stratified random sampling adalah teknik yang digunakan bila populasi mempunyai anggota/unsur yang tidak homogen dan berstrata secara proporsional (Umar, 2008), sebagai berikut :

$\mathrm{ni}=\frac{\mathrm{Ni}}{\mathrm{N}} \times \mathrm{n}$

Dimana :

$\mathrm{ni}=$ Jumlah sampel

$\mathrm{Ni}=$ Jumlah populasi per bagian

$\mathrm{N}=$ Jumlah populasi

Tabel 3. Perhitungan Jumlah Sampel

\begin{tabular}{cccc}
\hline Lokasi Penelitian & Cabang & Polulasi & Sampel \\
\hline & PT. Hasjrat Abadi Mutiara & 58 & 21 \\
$\begin{array}{c}\text { PT. Hasjrat } \\
\text { Abadi Palu }\end{array}$ & PT. Hasjrat Abadi Ponegoro & 92 & 34 \\
& PT. Hasjrat Abadi Durian & 20 & 8 \\
& Total & $\mathbf{1 7 0}$ & $\mathbf{6 3}$ \\
\hline
\end{tabular}

Sumber : Data primer yang diolah kembali

\section{Teknik Penarikan Sampel}

Teknik penarikan sampel yang digunakan pada penelitian ini dengan menggunakan teknik simple random sampling. Menurut (Sugiyono, 2014). Simple random sampling adalah teknik pengambilan sampel dari anggota populasi yang dilakukan secara acak tanpa memperhatikan strata yang ada dalam populasi itu.

\section{Operasionalisasi Variabel}

Definisi operasional variabel penelitian ini adalah sebagai berikut:

1. Lingkungan kerja adalah tempat dimana karyawan melaksanakan aktivitas pekerjaan setiap harinya. 
2. Budaya kerja adalah suatu falsafah yang dilandasi pandangan hidup dan tergambar pada sikap dari anggota organisasi.

3. Motivasi kerja adalah alasan yang melatarbelakangi sebuah tindakan yang dilakukan oleh seorang individu.

4. Kepuasan kerja adalah sesuatu yang bersifat individual, karena setiap individu memiliki tingkat kepuasan yang berbeda-beda sesuai dengan nilai-nilai yang berlaku dalam diri setiap individu tersebut.

5. Disiplin kerja adalah sikap atau kesediaan seseorang untuk taat dan patuh terhadap aturan yang berlaku dalam suatu organisasi.

6. Stres kerja adalah kondisi ketidakseimbangan secara psikologis yang dialami karyawan dalam menjalani pekerjaannya, yang dituangkan dalam bentuk emosi dan tingkah laku yang berbeda daripada biasanya.

7. Kinerja karyawan adalah hasil kerja baik secara kualitas maupun kuantitas yang dicapai seseorang dalam melaksanakan tugas sesuai tanggung jawab yang diberikan.

Tabel 4. Matriks Operasionalisasi Variabel

\begin{tabular}{|c|c|c|c|}
\hline Variabel & Dimensi & Indikator & $\begin{array}{l}\text { Skala } \\
\text { Ukur }\end{array}$ \\
\hline \multirow{5}{*}{$\begin{array}{l}\text { Lingkungan } \\
\text { kerja } \\
\text { Sondang } \\
(2017)\end{array}$} & Lingkungan & Bangunan tempat kerja & \multirow{5}{*}{ Ordinal } \\
\hline & & Peralatan kerja yang memadai & \\
\hline & & Fasilitas & \\
\hline & Lingkungan & Hubungan rekan kerja setingkat & \\
\hline & & Hubungan atasan dengan karyawan & \\
\hline \multirow{3}{*}{$\begin{array}{l}\text { Budaya kerja } \\
\text { Taliziduhu } \\
\text { (2012) }\end{array}$} & Unsur-unsur & Sikap terhadap pekerjaan & \multirow{3}{*}{ Ordinal } \\
\hline & & Perilaku ketika bekerja & \\
\hline & & Etos kerja & \\
\hline \multirow{2}{*}{$\begin{array}{l}\text { Motivasi kerja } \\
\text { Hasibuan } \\
\text { (2016) }\end{array}$} & Motivasi positif & $\begin{array}{l}\text { Memberikan hadiah kepada yang } \\
\text { berprestasi }\end{array}$ & \\
\hline & $\begin{array}{l}\text { Motivasi } \\
\text { negatif }\end{array}$ & $\begin{array}{l}\text { Memberikan hukuman kepada } \\
\text { karyawan yang pekerjaanya kurang } \\
\text { baik }\end{array}$ & Ordinal \\
\hline \multirow{2}{*}{$\begin{array}{l}\text { Kepuasan } \\
\text { kerja Sutrisno } \\
\text { (2016) }\end{array}$} & \multirow{3}{*}{$\begin{array}{l}\text { Faktor-faktor } \\
\text { kepuasan kerja }\end{array}$} & Kedudukan & \multirow{3}{*}{ Ordinal } \\
\hline & & Jaminan finansial dan sosial & \\
\hline \multirow{5}{*}{$\begin{array}{l}\text { Displin kerja } \\
\text { Sutrisno (2016) }\end{array}$} & & Mutu pengawasan & \\
\hline & \multirow{4}{*}{$\begin{array}{l}\text { Faktor- } \\
\text { faktor yang } \\
\text { mempengaruhi } \\
\text { disiplin kerja }\end{array}$} & Keteladanan pemimpin & \multirow{4}{*}{ Ordinal } \\
\hline & & Adanya pengawasan pemimpin & \\
\hline & & Aturan yang dijadikan pegangan & \\
\hline & & Perhatian kepada karyawan & \\
\hline
\end{tabular}




\begin{tabular}{|c|c|c|c|}
\hline Variabel & Dimensi & Indikator & $\begin{array}{l}\text { Skala } \\
\text { Ukur }\end{array}$ \\
\hline \multirow{4}{*}{$\begin{array}{l}\text { Stres kerja } \\
\text { Sondang } \\
\text { (2017) }\end{array}$} & \multirow{4}{*}{$\begin{array}{l}\text { Sumber- } \\
\text { sumber stres } \\
\text { kerja }\end{array}$} & Beban tugas terlalu berat & \multirow{4}{*}{ Ordinal } \\
\hline & & Desakan waktu & \\
\hline & & $\begin{array}{l}\text { Ketidakseimbangan antara wewenang } \\
\text { dan tanggung jawab }\end{array}$ & \\
\hline & & Masalah keuangan & \\
\hline \multirow{4}{*}{$\begin{array}{l}\text { Kinerja } \\
\text { karyawan } \\
\text { (Yani, 2012) }\end{array}$} & \multirow{4}{*}{$\begin{array}{l}\text { Penilaian } \\
\text { kinerja }\end{array}$} & Loyalitas & \multirow{4}{*}{ Ordinal } \\
\hline & & Semangat kerja & \\
\hline & & Kerjasama & \\
\hline & & Tanggung jawab & \\
\hline
\end{tabular}

Sumber: Data diolah kembali dari jurnal, 2020

\section{Teknik Pengujian Instrumen}

\section{Uji validitas}

Uji validitas adalah sejauh mana kehandalan sebuah alat ukur dalam mengukur apa yang diukur. Instrumen yang valid berarti alat ukur yang digunakan untuk mendapatkan data itu valid. Valid berarti instrumen tersebut dapat digunakan untuk mengukur apa yang seharusnya diukur (Sugiyono, 2014). Syarat minimum untuk dianggap memenuhi syarat adalah $\mathrm{r}=0$,3. Jadi, korelasi antara butir dengan skor total kurang dari 0,3 maka butir dalam instrumen tersebut dinyatakan tidak valid. Sebaliknya, jika skor total positif dan lebih besar dari 0,3 ( $r>0,3$ ) maka instrumen tersebut dinyatakan valid (Sugiyono, 2014).

\section{Uji reliabilitas}

Reliabilitas suatu alat pengukur menunjukan konsistensi hasil pengukuran sekiranya alat pengukur itu digunakan oleh orang yang sama dalam waktu yang berlainan atau digunakan oleh orang yang berlainan dalam waktu yang bersamaan atau waktu yang berlainan (Sanusi 2011). Dalam penelitian ini uji reliabilitas digunakan dengan menggunakan teknik uji coba cronbach alpha (a). Sugiyono $(2014,136)$ menambahkan bahwa : "suatu konstruk atau variabel dikatakan reliabel jika memberikan nilai cronbach alpha $>0,60 "$.

\section{Analisis Regresi Linear Berganda}

Dalam penelitian ini digunakan metode analisis regresi linier berganda. Adapun formulasi model penelitian ini, dapat ditulis sebagai berikut:

$$
\mathrm{Y}=\mathrm{a}+\mathrm{b}_{1} \mathrm{X}_{1}+\mathrm{b}_{2} \mathrm{X}_{2}+\mathrm{b}_{3} \mathrm{X}_{3}+\mathrm{b}_{4} \mathrm{X}_{4}+\mathrm{b}_{5} \mathrm{X}_{5}+\mathrm{b}_{6} \mathrm{X}_{6}+
$$


Dimana :

$\mathrm{Y}=$ Kinerja karyawan

$\mathrm{X}_{1}=$ Lingkungan kerja

$\mathrm{X}_{2}=$ Budaya kerja

$\mathrm{X}_{3}=$ Motivasi kerja

$\mathrm{X}_{4}=$ Kepuasan kerja

$\mathrm{X}_{5}=$ Disiplin kerja

$\mathrm{X}_{6}=$ Stres kerja

$\mathrm{a}=$ Konstanta

$\mathrm{b}$ = Paramater koefisien regresi masing-masing $\mathrm{x}$

e = Variabel gangguan (standar error).

\section{HASIL DAN PEMBAHASAN}

\section{Statistik Deskriptif Responden}

Berdasarkan hasil perhitungan statistik diketahui bahwa responden yang berumur 18 - 25 tahun sebanyak 21 orang dengan persentase sebesar 33,33 persen. Responden yang berumur 26 - 35 tahun sebanyak 39 orang dengan persentase 61,9 persen. Sedangkan responden, dengan umur 36 keatas sebanyak 3 orang dengan persentase sebesar 4,77 persen. Jadi dapat disimpulkan, bahwa mayoritas responden yang mengisi kuisioner penelitian ini adalah mereka yang berumur antara 26 - 35 tahun. Kemudian, responden dengan masa kerja 0 - 5 tahun sebanyak 42 orang dengan persentase 66,67 persen, responden dengan masa kerja 6 - 10 tahun sebanyak 17 orang dengan persentase 26,98 persen. Responden dengan masa kerja 11 tahun keatas sebanyak 4 orang dengan persentase 6,35 persen. Oleh karena itu, responden yang mengisi kuisioner didominasi oleh responden dengan masa kerja 0 - 5 tahun.

\section{Hasil Uji Validitas dan Reliabilitas}

Hasil uji validitas tabel 5 diketahui bahwa $\mathrm{r}$ table $=0,3$ dan nilai $\mathrm{r}$ hitung diperoleh pada corrected item-total correlation. Pada item pernyataan dari setiap variabel lebih besar dari nilai r tabel. Angka ini berarti menginformasikan bahwa semua butir kuisioner pada penelitian ini dinyatakan valid (andal).

Tabel 5. Hasil Uji Validitas

\begin{tabular}{ccccc}
\hline Variabel & $\begin{array}{c}\text { Item } \\
\text { Pernyataan }\end{array}$ & $\begin{array}{c}\text { Correted item-total } \\
\text { Correlation }\end{array}$ & r-kritis & Status \\
\hline Lingkungan Kerja & 1 & 0,768 & 0,3 & Valid \\
& 2 & 0,884 & 0,3 & Valid \\
3 & 0,873 & 0,3 & Valid \\
4 & 0,752 & 0,3 & Valid \\
5 & 0,823 & 0,3 & Valid
\end{tabular}


Syamsul, Fadel Muhammad | Studi Faktor Penentu Kinerja Karyawan PT. Hasjrat Abadi Palu

\begin{tabular}{|c|c|c|c|c|}
\hline Variabel & $\begin{array}{c}\text { Item } \\
\text { Pernyataan }\end{array}$ & $\begin{array}{l}\text { Correted item-total } \\
\text { Correlation }\end{array}$ & r-kritis & Status \\
\hline \multirow[t]{3}{*}{ Budaya Kerja } & 1 & 0,891 & 0,3 & Valid \\
\hline & 2 & 0,930 & 0,3 & Valid \\
\hline & 3 & 0,901 & 0,3 & Valid \\
\hline \multirow[t]{2}{*}{ Motivasi Kerja } & 1 & 0,887 & 0,3 & Valid \\
\hline & 2 & 0,817 & 0,3 & Valid \\
\hline \multirow[t]{3}{*}{ Kepuasan Kerja } & 1 & 0,653 & 0,3 & Valid \\
\hline & 2 & 0,854 & 0,3 & Valid \\
\hline & 3 & 0,781 & 0,3 & Valid \\
\hline \multirow[t]{4}{*}{ Disiplin Kerja } & 1 & 0,694 & 0,3 & Valid \\
\hline & 2 & 0,856 & 0,3 & Valid \\
\hline & 3 & 0,791 & 0,3 & Valid \\
\hline & 4 & 0,839 & 0,3 & Valid \\
\hline \multirow[t]{5}{*}{ Stress Kerja } & 1 & 0,655 & 0,3 & Valid \\
\hline & 2 & 0,759 & 0,3 & Valid \\
\hline & 3 & 0,652 & 0,3 & Valid \\
\hline & 4 & 0,738 & 0,3 & Valid \\
\hline & 5 & 0,649 & 0,3 & Valid \\
\hline \multirow[t]{4}{*}{ Kinerja Karyawan } & 1 & 0,765 & 0,3 & Valid \\
\hline & 2 & 0,853 & 0,3 & Valid \\
\hline & 3 & 0,608 & 0,3 & Valid \\
\hline & 4 & 0,729 & 0,3 & Valid \\
\hline
\end{tabular}

Sumber: Luaran SPSS

Merujuk pada tabel 6 menunjukkan bahwa semua variabel memiliki nilai croncbach's alpha $>0.60$, sehingga dinyatakan reliable atau layak.

Tabel 6. Hasil Uji Realibilitas

\begin{tabular}{lccc}
\hline \multicolumn{1}{c}{ Variabel } & Cronchbach Alpha & Standar Alpha & Keterangan \\
\hline Lingkungan Kerja & 0,878 & 0,60 & Valid \\
Budaya Kerja & 0,892 & 0,60 & Valid \\
Motivasi Kerja & 0,618 & 0,60 & Valid \\
Kepuasan Kerja & 0,650 & 0,60 & Valid \\
Disiplin Kerja & 0,805 & 0,60 & Valid \\
Stress Kerja & 0,723 & 0,60 & Valid \\
Kinerja Karyawan & 0,727 & 0,60 & Valid \\
\hline
\end{tabular}

Sumber: Luaran SPSS 


\section{Uji Normalitas}

Pengujian yang dilakukan untuk mengetahui apakah sebaran data mengikuti sebaran baku normal atau tidak dengan menggunakan uji statistic kolmogrov-Smirnov(K-S). Jika nilainya diatas 0,05 maka distribusi data dinyatakan memenuhi asumsi normaliatas, dan jika nilainya di bawah 0.05 maka diinterprestasikan sebagai normal. Melihat pada tabel 7 , menunjukan bahwa hasil asymp sig (2-tailed) adalah 0,882 yang mana berarti nilai sig (2-tailed) $>0,05$, dengan demikian model regresi ini terdistribusi dengan normal.

Tabel 7. One-Sample Kolmogorov-Smirnov Test

\begin{tabular}{lll}
\hline & & Unstandardized Residual \\
\hline $\mathrm{N}$ Normal Parameters & & 63 \\
& Mean & .0000000 \\
Most Extreme Differences & Std. Deviation & 1.16263806 \\
& Absolute & .079 \\
& Positive & .048 \\
Kolmogorov-Smirnov Z & Negative & -.079 \\
Asymp. Sig. (2-tailed) & & .630 \\
& & .822 \\
\hline
\end{tabular}

Sumber: Luaran SPSS

\section{Uji Multikolinearitas}

Hasil tabel 8 menunjukkan bahwa tidak ditemukan nilai korelasi antara variabel independen dikarenakan nilai tolerance $>$ 0,10 maka dapat disimpulkan tidak terjadi multikolineritas diantara variabel independen.

Tabel 8. Uji Multikolinearitas

\begin{tabular}{lccl}
\hline \multicolumn{1}{c}{ Variabel Independen } & \multicolumn{2}{c}{ Collinearity Statistics } & Keterangan \\
& Tolerence & VIF & \\
\hline Linkungan Kerja & .550 & 1.819 & Non Multikolinearitas \\
Budaya Kerja & .534 & 1.874 & Non Multikolinearitas \\
Motivasi Kerja & .657 & 1.522 & Non Multikolinearitas \\
Kepuasan Kerja & .515 & 1.943 & Non Multikolinearitas \\
Disiplin Kerja & .614 & 1.630 & Non Multikolinearitas \\
Stres Kerja & .730 & 1.370 & Non Multikolinearitas \\
\hline
\end{tabular}

Sumber: Luaran, SPSS 


\section{Uji Heteroskedastisitas}

Berdasarkan uji heteroskedasitas dengan uji glejser pada tabel 9 diperoleh nilai signifikasi lebih besar dari 0,05. Jadi dapat disimpulkan, bahwa model regresi tidak terjadi masalah heterokedasitas.

Tabel 9. Uji glejser

\begin{tabular}{lccccc}
\hline \multicolumn{1}{c}{ Model } & Unstandardized Coefficients & $\begin{array}{c}\text { Standardized } \\
\text { Coefficients }\end{array}$ & $\mathrm{t}$ & Sig. \\
& $\mathrm{B}$ & Std. Error & Beta & & \\
\hline $\begin{array}{l}\text { (Constant) } \\
\text { Linkungan }\end{array}$ & -.255 & .813 & & -.314 & .755 \\
Kerja & .063 & .045 & .230 & 1.380 & .173 \\
Budaya Kerja & .051 & .068 & .128 & .759 & .451 \\
$\begin{array}{l}\text { Motivasi } \\
\text { Kerja }\end{array}$ & .152 & .103 & .226 & 1.480 & .145 \\
$\begin{array}{l}\text { Kepuasan } \\
\text { Kerja }\end{array}$ & -.095 & .086 & -.191 & -1.106 & .273 \\
$\begin{array}{l}\text { Disiplin Kerja } \\
\text { Stres Kerja }\end{array}$ & -.078 & .057 & -.215 & -1.362 & .179 \\
\hline
\end{tabular}

Sumber. Luaran, SPSS

\section{Analisis Regresi Linear Berganda}

Analisis regresi linear berganda, dilakukan untuk mencari pengaruh lingkungan kerja, budaya kerja, motivasi kerja, kepuasan kerja, disiplin kerja, dan stres kerja terhadap kinerja karyawan. Hasil regeresi pada tabel 10, nilai R Square adalah 0,626 menunjukkan besarnya kontribusi variabel independen secara simultan terhadap variabel dependen, atau dengan kata lain besarnya kontribusi yang diberikan 62,6 persen. Sementara nilai koefisien korelasi (R) memberikan arti tingkat keeratan variabel independen dengan variabel dependen, semakin tinggi nilai koofisien maka hubungan antar variabel semakin erat, hasil analisis menunjukkan bahwa besaran koefisien korelasi R adalah sebesar 0,791 (79,1\%). Hal ini berarti tingkat keeratan variabel tersebut adalah kuat. 
Syamsul, Fadel Muhammad | Studi Faktor Penentu Kinerja Karyawan PT. Hasjrat Abadi Palu

Tabel 10. Hasil Perhitungan Regresi Linear Berganda

\begin{tabular}{llrrrrr}
\hline & \multicolumn{2}{c}{$\begin{array}{l}\text { Unstandardized } \\
\text { Coefficients }\end{array}$} & \multicolumn{2}{c}{$\begin{array}{c}\text { Standardized } \\
\text { Coefficients }\end{array}$} & \multicolumn{1}{c}{ T } & Sig. \\
& \multicolumn{1}{c}{ B } & Std. Error & Beta & & \\
\hline 1 & (Constant) & 1.683 & 1.458 & & 1.154 & .253 \\
& Lingkungan & .216 & .082 & .292 & 2.646 & .011 \\
& Budaya & .247 & .121 & .228 & 2.036 & .046 \\
Motivasi & .098 & .184 & .054 & .532 & .597 \\
Kepuasan & .543 & .155 & .400 & 3.513 & .001 \\
Disiplin & -.170 & .102 & -.174 & -1.666 & .101 \\
Stres & .178 & .083 & .205 & 2.140 & .037
\end{tabular}

a. Dependen Variable: Kinerja Karyawan

$\begin{array}{llll}\text { Mulitple R } & : .791^{\mathrm{a}} & & \text { F hitung } \\ \text { R squere } & : .626 & \text { Sig. F } & : .616 \\ \text { Adjusted R square } & : .586 & & .000^{\mathrm{a}}\end{array}$

Sumber: Luaran SPSS

Berdasarkan hasil perhitungan pada tabel 10 dapat dijelaskan nilai koefisien regresi lingkungan kerja sebesar 0,292 dengan nilai signifikansi sebesar 0,011. Angka ini menunjukkan lingkungan kerja mempunyai pengaruh positif sebesar 29,2 persen dan signifikan $(0,011<0,05)$ terhadap kinerja karyawan. Hal ini mengandung arti bahwa $\mathrm{H1}$ tidak dapat ditolak. Kemudian, nilai koefisien regresi budaya kerja sebesar 0,228 dan nilai signifikansi sebesar 0,046. Fakta ini menunjukkan budaya kerja mempunyai pengaruh positif sebesar 22,8 persen dan signifikan $(0,046<0,05)$ terhadap kinerja karyawan, karena itu, H2 diterima. Selanjutnya, koefisien motivasi kerja sebesar 0,054 dan signifikansinya sebesar 0,597. Nilai ini menginformasikan motivasi kerja mempunyai hubungan yang searah sebesar 5,4 persen dengan kinerja karyawan tetapi tidak signifikan $(0,054>0,05)$. Artinya, H3 yang diajukan tidak dapat diterima. Nilai koefisien kepuasan kerja sebesar 0,400 dengan nilai signifikansi sebesar 0,001. Maka, angka ini mengindikasikan kepuasan kerja mempunyai pengaruh yang searah sebesar 40 persen dan signifikan $(0,001<0,05)$ terhadap kinerja karyawan. Maknanya, H4 diterima. Selain itu, nilai koefisien disiplin kerja sebesar -0,174 dengan nilai signifikansi sebesar 0,101, sehingga dispilin kerja tidak mempunyai pengaruh yang searah dan tidak signifikan $(0,101>0,05)$ terhadap kinerja karyawan. Oleh karena itu, H5 ditolak. Sementara itu, nilai koefisien stres kerja sebesar 0,205 dengan nilai signifikansi 0,037. Fakta ini menunjukkan stres kerja mempunyai pengaruh positif sebesar 20,5 persen dan signifikan $(0,037<0,05)$ terhadap kinerja karyawan. Hal tersebut mengandung arti H6 diterima. 
Syamsul, Fadel Muhammad | Studi Faktor Penentu Kinerja Karyawan PT. Hasjrat Abadi Palu

\section{PEMBAHASAN}

\section{Pengaruh Lingkungan Kerja Terhadap Kinerja Karyawan}

Hasil analisis regresi melalui uji hipotesis, penelitian ini mendukung hipotesis 1, bahwa lingkungan kerja berpengaruh positif dan signifikan terhadap kinerja karyawan PT Hasjrat Abadi Palu. Artinya, semakin kondusif lingkungan kerja suatu perusahaan berbanding lurus dengan peningkatan kinerja karyawan di perusahaan tersebut. Hasil ini pararel dengan penelitian sebelumnya dilakukan oleh Adha, Qomariah and Hafidzi (2019) pada Dinas Sosial Kabupaten Jember; Primandaru, Tobing and Prihatini (2018) pada PT Kereta Api Indonesia (Persero) Daop IX Jember; Prastiyo (2019) pada JNE Cabang Madiun; Lukito and Alriani (2018) pada PT Sinarmas Distribusi Nusantara Semarang; Malau (2020) PT Sansyu Prcision Batam, yang menemukan bahwa lingkungan kerja berpengaruh positif terhadap kinerja karyawan. Dengan demikian, temuan ini menginformasikan pentingnya manajemen perusahaan memperhatikan lingkungan kerja perusahaan agar tetap kondusif guna mendukung kinerja karyawan yang lebih optimal.

\section{Pengaruh Budaya Kerja Terhadap Kinerja Karyawan}

Hasil analisis menunjukkan bahwa hipotesis 2 yang diajukan pada penelitian ini diterima, yaitu terdapat pengaruh positif dan signifikan budaya kerja terhadap kinerja karyawan PT Hasjrat Abadi Palu. Maknanya, semakin berkualitas budaya kerja karyawan berimplikasi pada peningkatan kinerja karyawan di dalam sebuah perusahaan. Temuan ini juga didukung oleh penelitian sebelumnya, yang dilakukan oleh Anggeline, Meitriana and Sujana (2019) pada PT BPR Nusamba Kubutambahan; Adha, Qomariah and Hafidzi (2019) pada Dinas Sosial Kabupaten Jember; Panggabean, Soekapdjo and Tribudhi (2020) pada perusahaan swasta di Jakarta, juga telah membuktikan bahwa budaya kerja berpengaruh positif dan signifikan terhadap kinerja karyawan. Selain itu, temuan ini juga mengindikasikan bahwa budaya kerja memiliki peran penting dalam mendorong karyawan bekerja lebih baik dan memiliki motivasi yang tinggi, serta dapat menciptakan suasana yang kondusif yang pada akhirnya mendorong kinerja kerja karyawan.

\section{Pengaruh Motivasi Kerja Terhadap Kinerja Karyawan}

Berdasarkan model regresi, hipotesis 3 yang diajukan tidak terdukung, berarti motivasi kerja tidak berpengaruh signifikan terhadap kinerja karyawan PT Hasjrat Abadi Palu. Temuan ini sejalan dengan penelitian (lihat, Setyawan, 2018; Harahap and Tirtayasa, 2020) yang menunjukkan bahwa tidak ada pengaruh yang signifikan antara motivasi kerja dengan kinerja karyawan. Disisi lain, hasil ini bertolakbelakang dengan penelitian yang dilakukan oleh Primandaru, Tobing and Prihatini (2018) pada PT Kereta Api Indonesia (Persero) Daop IX Jember; Ayer, Pangemanan and Rori (2016) pada Dinas Pertanian Kabupaten Supiori, yang menjelaskan tentang pengaruh positif yang signifikan antara motivasi kerja dengan kinerja karyawan. Hasil ini mengindikasikan perlunya memancing motivasi kerja para karyawan, sehingga mereka memiliki semangat kerja untuk mencapai sebuah tujuan. Motivasi yang tinggi juga akan menjadikan karyawan 
untuk melakukan pekerjaannya dengan baik. Pemberian penghargaan, kompensasi atau bonus bagi karyawan yang berprestasi merupakan salah satu bentuk untuk meningkatkan motivasi karyawan dalam bekerja.

\section{Pengaruh Kepuasan Kerja Terhadap Kinerja Karyawan}

Hasil analisis regresi mendukung hipotesis 5, bahwa kepuasan kerja berpengaruh positif dan signifikan terhadap kinerja karyawan PT Hasjrat Abadi Palu. Intinya, semakin tinggi kepuasan kerja yang dirasakan oleh seorang karyawan berdampak positif pada peningkatan kinerja karyawan di dalam sebuah perusahaan. Hasil sesuai dengan penelitian (lihat, Primandaru, Tobing and Prihatini, 2018; Khusnah, 2019; Asmawiyah and Mukhtar, 2020; Harahap and Tirtayasa, 2020), menemukan bahwa kepuasan kerja berpengaruh positif dan signifikan terhadap kinerja karyawan. Oleh karena itu, manajemen perusahaan harus berupaya menciptakan kepuasan kerja karyawan dengan sebaik-baiknya, guna mendorong peningkatan kinerja karyawan. Beberapa indikator yang dapat memunculkan kepuasan kerja karyawan yaitu ketika mereka ditempatkan pada posisi atau jabatan yang sesuai dengan keahliannya, dan memiliki jaminan masa tua, serta adanya pengawasan kepada mereka.

\section{Pengaruh Disiplin Kerja Terhadap Kinerja Karyawan}

Berdasarkan hasil analisis menunjukkan bahwa hipotesis 6 tidak terdukung, dengan demikian disiplin kerja tidak berpengaruh positif terhadap kinerja karyawan PT Hasjrat Abadi Palu. Hasil ini tidak konsisten dengan penelitian (lihat, Primandaru, Tobing and Prihatini, 2018; Setyawati, Aryani and Ningrum, 2018; Harahap and Tirtayasa, 2020; Malau, 2020), yang menemukan bahwa disiplin kerja berpengaruh positif dan signifikan terhadap kinerja karyawan. Di dalam literatur ditemukan bahwa disiplin kerja dapat meningkatkan kinerja karyawan, sedangkan hasil penelitian ini tidak terbukti. Berdasarkan observasi dan wawancara dilapangan menunjukkan bahwa terdapat beberapa indikator yang mempengaruhi tidak signifikannya disiplin kerja. Beberapa indikator tersebut, yaitu keteladanan, pengawasan, ketaatan pada peraturan kerja dan etika kerja. Oleh karena itu, perlu adanya perhatian penuh dari pimpinan terhadap bawahannya untuk meningkatkan kedisiplinan karyawan. Disiplin kerja menggabarkan sebuah kondisi atau sikap hormat yang terdapat pada diri setiap karyawan atas kebijakan perusahaan. Dengan demikian, apabila karyawan tunduk dan patuh pada ketetapan perusahaan, menggambarkan adanya kondisi disiplin yang baik. Sementara itu, apabila peraturan atau ketetapan tersebut diabaikan, atau sering dilanggar, maka karyawan mempunyai disiplin yang buruk. Logikanya, jika displin kerja diterapkan oleh semua karyawan dengan baik, maka akan menghasilkan kinerja yang baik pula.

\section{Pengaruh Stres Kerja Terhadap Kinerja Karyawan}

Hasil analisis regresi menunjukkan bahwa hipotesis 6 terdukung, bahwa stres kerja berpengaruh positif dan signifikan terhadap kinerja karyawan PT Hasjrat Abadi Palu. Artinya, tingginya stres kerja yang dialami karyawan berbanding lurus dengan 
peningkatan kinerja karyawan tersebut. Temuan ini sejalan dengan Prastiyo (2019) pada JNE Cabang Madiun; Effendy and Fitria (2019) pada PT. Modernland Realty, Tbk, Jakarta Selatan, membuktikan bahwa stres kerja berpengaruh positif dan signifkan terhadap kinerja karyawan. Disisi lain, hasil penelitian (lihat, Pinatih and Gorda, 2017; Lukito and Alriani, 2018; Setyawati, Aryani and Ningrum, 2018) menunjukkan sebaliknya, bahwa stres kerja berpengaruh negatif terhadap kinerja karyawan. Menurut Handoko (2001) sejalan dengan meningkatnya stres dapat membantu karyawan untuk mengarahkan segala sumber daya yang dimilikinya dalam memenuhi berbagai persyaratan atau kebutuhan pekerjaan. Intinya, stres apabila tidak terkelola dengan baik, berdampak pada penurunan kinerja karyawan, sementara jika stres itu dapat ditangani dengan baik, justru akan berimplikasi pada peningkatan kinerja.

\section{SIMPULAN, KETERBATASAN, DAN SARAN}

Penelitian ini bertujuan untuk mengetahui pengaruh lingkungan kerja, budaya kerja, motivasi kerja, kepuasan kerja, disiplin kerja, dan stres kerja terhadap kinerja karyawan PT. Hasjrat Abadi Palu. Hasil analisis regresi menunjukkan bahwa lingkungan kerja, budaya kerja, kepuasan kerja, dan stres kerja secara parsial berpengaruh dan signifikan terhadap kinerja karyawan. Sementara itu, motivasi kerja dan disiplin kerja tidak berpengaruh secara signifikan terhadap kinerja karyawan. Berdasarkan temuan ini, maka dapat diajukan saran atau rekomendasi kepada pimpinan perusahaan PT. Hasjrat Abadi Palu yaitu untuk lebih mengenali dan memperhatikan faktor-faktor yang dapat meningkatkan motivasi kerja seperti memberikan perhatian khusus atau memberikan reward kepada karyawan yang berperan penting dibidangnya masing-masing. Tujuannya, untuk meningkatkan kinerja karyawan sehingga menghasilkan pencapaian perusahaan yang baik. Kemudian, lebih memperhatikan disiplin kerja terhadap diri sendiri sebelum diterapkan kepada karyawan. Karena pimpinan akan jadi contoh kepada karyawan untuk mematuhi aturan-aturan yang ada pada perusahaan, sebab disiplin kerja akan terlaksana dengan baik jika aturan-aturan tersebut dapat dipatuhi. Terakhir, untuk mengatasi tingkat stres kerja karyawan pimpinan perlu mengatur pemberian tugas beserta memberikan wewenang yang seimbang dengan tanggung jawab yang diberikan kepada karyawan. Selain itu, jika pimpinan memberikan tugas waktunya tidak dekat deadline agar karyawan tidak merasa terdesak waktu dalam bekerja, sehingga dapat optimal dalam bekerja.

\section{DAFTAR PUSTAKA}

Adha, R. N., Qomariah, N. and Hafidzi, A. H. (2019) 'Pengaruh Motivasi Kerja, Lingkungan Kerja, Budaya Kerja Terhadap Kinerja Karyawan Dinas Sosial Kabupaten Jember', Jurnal Penelitian IPTEKS, 4(1), p. 47. doi: 10.32528/ipteks.v4i1.2109.

Anggeline, K. D. N., Meitriana, M. A. and Sujana, I. N. (2019) 'Pengaruh Budaya Kerja Terhadap Kinerja Karyawan Di Pt. Bpr Nusamba Kubutambahan', Jurnal Pendidikan Ekonomi Undiksha, 9(2), p. 441. doi: 10.23887/jjpe.v9i2.20121. 
Syamsul, Fadel Muhammad | Studi Faktor Penentu Kinerja Karyawan PT. Hasjrat Abadi Palu

Asmawiyah and Mukhtar, Af. (2020) 'Pengaruh Motivasi Kerja dan Kepuasan Kerja Terhadap Kinerja Karyawan', Jurnal Mirai Managemnt, 5(2), pp. 388-401. Available at: https://journal.stieamkop.ac.id/index.php/mirai.

Ayer, J. E., Pangemanan, L. R. . and Rori, Y. P. . (2016) 'PENGARUH MOTIVASI DAN DISIPLIN KERJA TERHADAP KINERJA PEGAWAI PADA DINAS PERTANIAN KABUPATEN SUPIORI', Agri-SosioEkonomi Unsrat, 12(November), pp. 27-46.

Effendy, A. A. and Fitria, J. R. (2019) 'Pengaruh Lingkungan Kerja Dan Stres Kerja Terhadap Kinerja Karyawan (Studi Kasus Pt. Modernland Realty, Tbk)', JIMF (Jurnal Ilmiah Manajemen Forkamma), 2(2), pp. 49-61. doi: 10.32493/frkm.v2i2.3406.

Handoko, T. H. (2001). Manajemen sumber daya manusia. Yogyakarta: BPFE.

Hasibuan, M. S., \& Hasibuan, H. M. S. (2016). Manajemen sumber daya manusia. Bumi Aksara.

Harahap, S. F. and Tirtayasa, S. (2020) 'Pengaruh Motivasi , Disiplin dan Kepuasan Kerja Terhadap Kinerja Karyawan Pada PT . Angkasa Pura II ( Persero ) Kantor Cabang Kualanamu', 3(1), pp. 120-135.

Heny, S. (2015) 'Pengaruh Lingkungan Kerja, Disiplin Kerja Dan Motivasi Kerja Terhadap Kinerja Pegawai Negeri Sipil Di Sekretariat Dprd Kabupaten Madiun', Jurnal JIBEKA, 9, pp. 44-53.

Ibrahim, R., Sasmita, J. and Putri, A. K. (2015) 'Pengaruh Stress Dan Disiplin Terhadap Produktivitas Kerja Karyawan Supporting Pada Pt. Indah Kiat Pulp and Paper Tbk Di Perawang', Jurnal Online Mahasiswa Fakultas Ekonomi Universitas Riau, 2(1), pp. 1-18.

Khusnah, H. (2019) 'Pengaruh Spiritualitas di Tempat Kerja, Komitmen Organisasi dan Kepuasan Kerja terhadap Kinerja Karyawan', Jurnal Ilmiah Akuntansi, 17(1), pp. $17-23$.

Leonardo Hendy Lukito and Alriani, I. M. (2018) 'Pengaruh Beban Kerja, Lingkungan Kerja, Stres Kerja Terhadap Kinerja Karyawan Pada PT. Sinarmas Distribusi Nusantara Semarang', Jurnal Ekonomi Manajemen dan Akuntansi, 45(25), pp. 24-35.

Malau, M. K. (2020) 'TERHADAP KINERJA KARYAWAN PADA PT . SANSYU PRECISION BATAM', 4(2), pp. 487-498.

Mangkunegara, A. A. P. (2005). Evaluasi kinerja SDM. Tiga Serangkai.

Mulyadi, D. and Syafitri, A. (2015) 'Pengaruh Kepemimpinan Dan Motivasi Kerja Terhadap Kinerja Karyawan Di Bank Bjb Syariah Cabang Bogor', Jurnal Ilmiah Binaniaga, 11(2), p. 33. doi: 10.33062/jib.v11i2.265.

Musanef (1996) Manajemen Kepegawaian Di Indonesia. Jakarta: PT. Toko Gunung Agung. Persada.

Nababan, E. and Siagian, M. (2020) 'Analisis Pengaruh Budaya Organisasi, Disiplin Kerja Dan Motivasi Terhadap Kinerja Karyawan PT Sanwa Engineering Batam', Jurnal Ilmiah Core It, 8(1).

Panggabean, M. S., Soekapdjo, S. and Tribudhi, D. A. (2020) 'Pengaruh budaya organisasi terhadap kinerja karyawan di era millennial', Akuntabel, 17(1), pp. 133-139. 
Pinatih, I. G. B. A. and Gorda, A. A. N. E. S. (2017) 'Gaya kepemimpinan, beban kerja, stres kerja, teknologi informasi, dan kinerja karyawan', Jurnal Ilmiah Manajemen \& Bisnis, 2(2), pp. 298-310. Available at: http://journal.undiknas.ac.id/index.php/manajemen.

Prastiyo, F. D. (2019) 'PENGARUH STRES KERJA, Lingkungan Kerja Dan Motivasi Kerja Terhadap Kinerja Karyawan Pada Jne Cabang Madiun', Strategic : Jurnal Pendidikan Manajemen Bisnis, 18(1), p. 23. doi: 10.17509/strategic.v18i1.17586.

Primandaru, D. L., Tobing, D. S. and Prihatini, D. (2018) 'Pengaruh Motivasi Kerja Dan Lingkungan Kerja Terhadap Kepuasan Kerja, Disiplin Kerja Dan Kinerja Karyawan Pt. Kereta Api Indonesia (Persero) Daop Ix Jember', Bisma, 12(2), p. 204. doi: 10.19184/ bisma.v12i2.7890.

Riyadi, S. (2011) 'Pengaruh Kompensasi Finansial , Gaya Kepemimpinan , dan Motivasi Kerja', Jurnal Manajemen dan Kewirausahaan, 13(1), pp. 40-45. doi: 10.9744/ jmk.13.1.40-45.

Saputra, I. P. A., Bagia, I. W. and Jurusan, I. W. S. (2016) 'pengaruh kompetensi dan disiplin kerja terhadap kinerja karyawan', e-Journal Bisma Universitas Pendidikan Ganesha, 4(1), pp. 121-130.

Sanusi. Anwar. (2011). Metode Penelilian Bisnis. Salemba Empat. Jakarta.

Siagian, S. P. (2017). Manajemen sumber daya manusia. Bumi Aksara.

Setyawan, A. (2018) 'Analisis Faktor-Faktor Yang Mempengaruhi Kinerja Karyawan Perusahaan Fabrikasi Lepas Pantai Di Batam Dan', Journal of Accounting \& Management Innovation, Volume 2(Nomor 1), pp. 67-89.

Setyawati, N. W., Aryani, N. A. and Ningrum, E. P. (2018) 'Stres Kerja Dan Disiplin Kerja Terhadap Kinerja Karyawan', Jurnal Riset Manajemen dan Bisnis (JRMB) Fakultas Ekonomi UNIAT, 3(3), pp. 405-412. doi: 10.36226/jrmb.v3i3.158.

Silvia, Bagia, I. W. and Cipta, W. (2016) 'Pengaruh Kompetensi dan Budaya Kerja Terhadap Kinerja Karyawan', e-Jurnal Bisma Universitas Pendidikan Ganesha, 4(1), pp. 1-10.

Sugiyono. (2014). Statistikauntuk penelitian. Bandung : Alfabeta.

Sutrisno Edi (2013). Manajemen Sumber Daya Manusia. Jakarta : prenanda Media Group. Edisi Pertama. Cetakan Kelima.

Taliziduhu, N. (2012). Budaya Kerja, Jakarta. Rineka Cipta.

Umar, H. (2008). Metode penelitian untuk skripsi dan tesis bisnis. PT RajaGrafindo

Yani, M. 2012. ManajemenSumberDayaManusia. Jakarta: Mitra Wacana Media. 